\title{
"Programa Saúde e Cidadania": a contribuição da extensão universitária na Amazônia para a formação médica
}

\author{
"Programa Saúde e Cidadania": the contribution of university extension in \\ Amazonia for medical education
}

\author{
Ricardo Gonçalves Martins ${ }^{1}$, Rosana Pimentel Correia Moysés ${ }^{2}$, Fabio Francesconi do Valle ${ }^{3}$, \\ Valeska Albuquerque Francesconi do Valle ${ }^{4}$, Celsa da Silva Moura Souza, \\ José Fernando Marques Barcellos ${ }^{6}$
}

\begin{abstract}
Martins RG, Moysés RPC, Valle FF, Valle VAF, Souza CSM, Barcellos JFM. "Programa Saúde e Cidadania": a contribuição da extensão universitária na Amazônia para a formação médica / "Programa Saúde e Cidadania": the contribution of university extension in Amazonia for medical education. Rev Med (São Paulo). 2016 jan.-mar.;95(1):6-11.

RESUMO: Com destaque à importância na formação médica, relata-se a experiência vivida por discentes e docentes de medicina em parceria com os residentes multiprofissionais em saúde num programa de extensão no interior do Amazonas. O resultado da imersão destes autores na realidade comunitária e de suas vivências práticas, individuais e coletivas, dentro do "Programa Saúde e Cidadania" em municípios do interior do Amazonas, entre fevereiro de 2012 e julho de 2015, é descrito numa abordagem qualitativa do tipo relato de experiência. Desde 2012, mais de 50 acadêmicos puderam estar presentes nas viagens de campo, programadas e executadas pelos próprios alunos sob orientação da equipe de coordenadores e docentes do Programa, em parceria com multiprofissionais da Residência Multiprofissional em Saúde da Universidade Federal do Amazonas (UFAM). Os graduandos do curso de medicina têm a oportunidade de imergir na realidade destas comunidades e, assim, vislumbrar o contexto social, as peculiaridades territoriais e os Determinantes Sociais em Saúde que influenciam no processo saúde-doença. As vivências neste programa de extensão colaboraram para integrar criticidade, humanização e trabalho em equipe à formação técnica da grade, possibilitando que se formem médicos mais sensíveis às propostas do Sistema Único de Saúde.

ABSTRACT: With emphasis to the importance in medical education, it reports the experience lived by the academics and teachers of medicine in partnership with the pupils of Health Multiprofissional Residence in an extension program in the interior of the Amazon. The result of the immersion of these authors in community reality and of their individual and collective experiences within the "Programa Saúde e Cidadania" in municipalities of Amazonas, between February 2012 and July 2015 , is described in a qualitative approach of the type experience report. Since 2012, more than 50 academics were able to be present in field trips, planned and executed by the students themselves under the guidance of the team of coordinators and teachers of the extension program in partnership of Helth Multiprofissional Residence from Ufam. The academics of medical school has the opportunity of immersing in the reality of these communities and thus glimpse the social context, the territorial peculiarities and Health Social Determinants which influence the health-disease process. The experiences in this extension program cooperated to integrate criticality, humanization and team work to technical training of curriculum providing the possibility of forming doctors more sensitive to the proposals of the Public Health Sistem.
\end{abstract}

DESCRITORES: Educação médica; Relações comunidadeinstituição; Aprendizagem; Educação em saúde.
KEYWORDS: Education, medical; Community-institutional relations; Learning; Health education.

Instituição de realização: Universidade Federal do Amazonas.

Agência de fomento: Secretaria de Educação Superior - Ministério da Educação.

1. Graduando em Medicina pela Universidade Federal do Amazonas (UFAM). Email: ricardogm89@gmail.com.

2. Cirurgiã-Dentista; Docente da Universidade Federal do Amazonas, Faculdade de Medicina, Departamento de Saúde Coletiva. E-mail: rosanapcsmsde@gmail.com.

3. Médico Dermatologista; Docente da Universidade Federal do Amazonas, Faculdade de Medicina, Departamento de Saúde Coletiva. E-mail: fabiofrancesconi@globo.com.

4. Médica Dermatologista da Fundação de Medicina Tropical Doutor Heitor Vieira Dourado (FMT-HVD). E-mail: valeska@francesconi.med.br.

5. Nutricionista; Docente da Universidade Federal do Amazonas, Faculdade de Medicina, Departamento de Saúde Coletiva. E-mail: celsa22@hotmail.com. 6. Biólogo; Docente da Universidade Federal do Amazonas, Instituto de Ciências Biológicas, Departamento de Morfologia. E-mail: f.marques123@gmail.com. Autor correspondente: Ricardo Gonçalves Martins. Universidade Federal do Amazonas, Faculdade de Medicina, Departamento de Saúde Coletiva. Rua Afonso Pena, 1053, Praça 14. CEP: 69029-170 - Manaus, AM, Brasil. E-mail: ricardogm89@gmail.com 


\section{INTRODUÇÃO}

S programas de extensão são previstos pelas Diretrizes Curriculares Nacionais do Curso de Graduação em Medicina (2014), como atividades complementares que devem ser articulados à organização do curso e estimuladas como ações que incitem a participação ativa do graduando na construção do conhecimento ${ }^{1}$.

A extensão universitária aproxima os docentes e os discentes da realidade regional e local, por intermédio de ações que integrem a teoria e os cenários de prática. Neste panorama, a imersão dos acadêmicos na comunidade mostra-se fundamental no que tange a formação pessoal e profissional do médico, por fortalecer o vínculo com a comunidade e agregar criticidade e humanização à formação técnica ${ }^{2,3}$.

As ações de extensão também ganham destaque pelos benefícios que trazem à comunidade, por terem um componente assistencial. E estas ações corroboram com a obrigação da Universidade de colocar como bem social toda a produção de conhecimento e priorizar o compromisso social como parte de sua missão $0^{4.5}$.

Assim, o objetivo deste estudo é relatar a experiência vivida por discentes e docentes de medicina, em parceria com os residentes multiprofissionais em saúde, nas atividades de um programa de extensão no interior do Amazonas, demonstrando a importância deste para a formação médica.

\section{METODOLOGIA}

O estudo é classificado como descritivo de abordagem qualitativa, do tipo relato de experiência. Deste modo, buscase esclarecer fatos sem mensurações quantitativas a partir da observação, registro, análise e interpretação de uma vivência de interesse da comunidade científica ${ }^{6,7,8}$.

O relato toma por base a imersão destes autores na realidade comunitária e suas vivências práticas, individuais e coletivas, na extensão universitária dentro do "Programa Saúde e Cidadania - Construindo uma Rede Social de Promoção da Saúde" em cinco municípios do interior do Amazonas: Itapiranga, Novo Airão, Itacoatiara, Silves e Urucurituba, entre fevereiro de 2012 e julho de 2015. As localidades em questão estão inclusas no programa federal "Territórios da Cidadania".

Para tanto, documentos de texto e planilhas, com dados epidemiológicos e registro do planejamento de campo, foram avaliados a fim de definir o padrão de organização das atividades desenvolvidas nos municípios. Os áudios de reuniões e das ações de promoção da saúde foram transcritos, e, além disso, junto com os diários de campo aplicou-se a técnica de leitura exaustiva para organização dos discursos, considerando como critério a relevância ${ }^{9}$.

Neste contexto foram consideradas falas que caracterizavam o planejamento e a execução das atividades realizadas; as peculiaridades da região amazônica, seu sistema de saúde e os Determinantes Sociais em Saúde; a interlocução entre a equipe, com ênfase na relação multiprofissional; e as contribuições e dificuldades da vivência em campo?.

As fotos e vídeos foram agrupados por município de registro, organizados por data e, então, avaliados para caracterização e quantitativo de público alvo, assim como a definição de representatividade das imagens, que, neste contexto, são as vivências regionais, a inclusão de representações sociais, a longitudinalidade das ações desenvolvidas e a integração entre serviço, ensino e comunidade 9 .

\section{O PROGRAMA SAÚDE E CIDADANIA - CONSTRUINDO UMA REDE SOCIAL DE PROMOÇÃO DA SAÚDE}

O programa do Governo Federal, Territórios da Cidadania, tem o objetivo de superar a pobreza e gerar trabalho e renda, por meio de inclusão produtiva. Assim, espera universalizar programas de cidadania e planejamento, mas também, integrar políticas públicas e ampliar a participação social. É diferenciado, pois tem a sua base no território-processo para atingir municípios com características socioeconômicas, ambientais e culturais semelhantes e por buscar o envolvimento civil na gestão territorial.

Neste ínterim surgiu o Programa Saúde e Cidadania - Construindo uma Rede Social de Promoção da Saúde, uma extensão universitária do Departamento de Saúde Coletiva da Faculdade de Medicina da Universidade Federal do Amazonas (UFAM).

O programa extensionista desenvolve atividades nas linhas de Promoção da Saúde e Prevenção de Doenças, Saúde da Mulher, Alimentação Saudável, Avaliação dos Serviços de Saúde e Dermatologia em cinco municípios ribeirinhos do interior do Amazonas, inclusos nos Territórios da Cidadania: Itapiranga, Novo Airão, Itacoatiara, Silves e Urucurituba.

A região amazônica é marcada pelo predomínio do transporte fluvial. As comunidades e cidades circundadas por água, muitas vezes, têm acesso exclusivo por meio de longas viagens de barco com duração de dias.

Parte dos municípios nos quais o Programa desenvolve atividades têm população inferior a 10 mil habitantes e estão entre os menores Índices de Desenvolvimento Humano (IDH) do país. As pessoas e comunidades possuem um forte traço cultural (crenças, costumes e linguagem), e convivem diariamente com barreiras físicas, sociais e organizacionais para o acesso à saúde.

Desde 2012, mais de 50 acadêmicos puderam estar presentes em excursões de campo nestes municípios. As viagens são programadas e executadas pelos próprios alunos, sob orientação da equipe de coordenadores e docentes do Programa, contando com a parceria de multiprofissionais (educadores físicos, enfermeiros, fisioterapeutas e nutricionistas) da Residência Multiprofissional em Saúde da UFAM, parceira do Programa de extensão.

Os graduandos em medicina têm a oportunidade de imergir na realidade destas comunidades e, assim, enxergar o contexto social, as peculiaridades territoriais e os Determinantes Sociais em Saúde, que influenciam no processo saúde-doença.

Nesta conjuntura ganha destaque a integração com os multiprofissionais em saúde, o que sensibiliza o discente de medicina quanto à maior abrangência nos cuidados em equipe $\mathrm{e}$ estimula a transdisciplinaridade nas ações que consideram visões complementares para o cuidado aos usuários.

A dinâmica de planejamento da viagem começa com reuniões prévias do grupo, na capital Manaus. Com isso, ocorre à familiarização do território por meio de informações geográficas e históricas, bancos de dados públicos em saúde e reportagens sobre cada município. Os municípios parceiros apresentam as necessidades que possuem, cria-se um roteiro inicial das atividades para a vivência e os materiais são separados para as ações de campo.

O reconhecimento do campo, por meio de contatos com 
gestores (prefeitos, assessores, secretários de saúde, líderes comunitários, entre outros) e análise de relatórios e indicadores de saúde locais, é feito com a chegada do grupo no município. Desta forma, os acadêmicos desenvolvem habilidades de planejamento de ações em saúde, considerando a necessidade e o contexto em que se insere o público alvo, adequando o planejamento inicial.
Os alunos realizam, junto com os docentes, os contatos necessários à execução das atividades de campo como transporte - normalmente fluvial na região amazônica (Figura 1) - e viabilidade de locais onde se possa concentrar o público alvo, como Unidades Básicas de Saúde (UBS), igrejas e grupos de idosos e jovens.

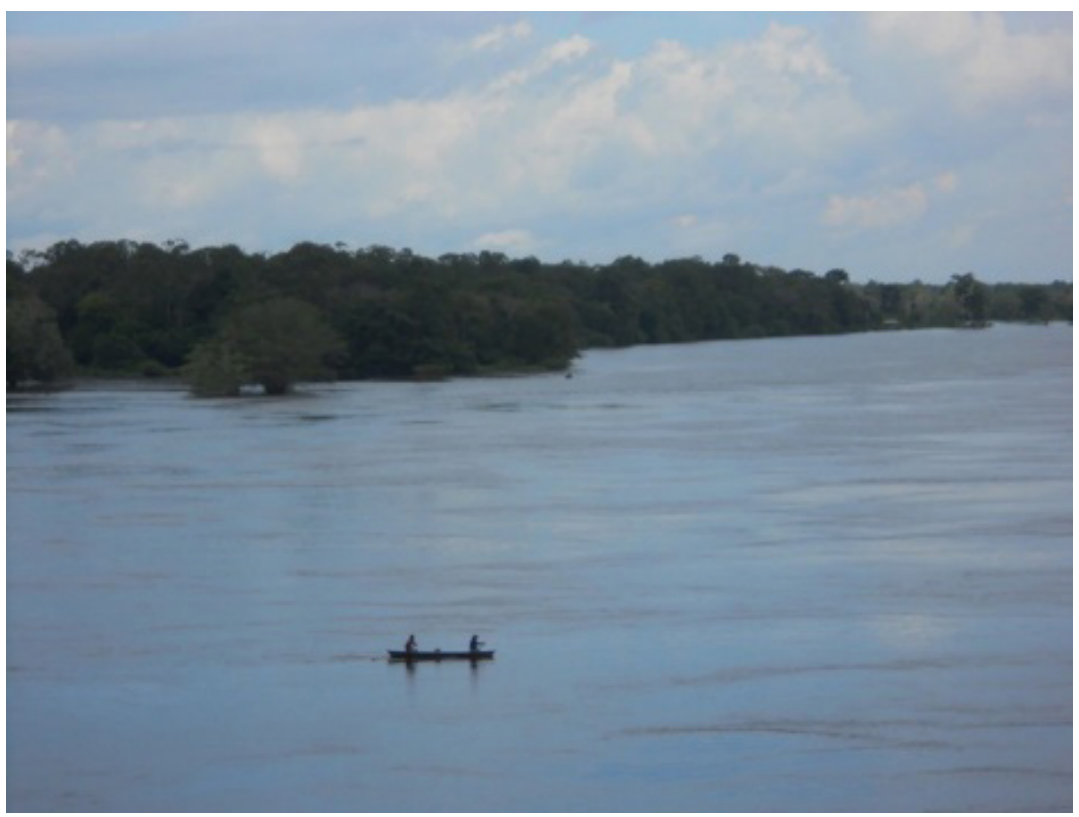

Figura 1. O canoeiro e o desafio do acesso: deslocamento por meio da principal via de transporte no interior do Amazonas, as águas

Assim sendo, empoderados do planejamento os acadêmicos aprimoram habilidades de liderança e organização de campo, essenciais ao profissional médico, que deve trabalhar em equipe.

Nos dias subsequentes, as atividades de cada linha são executadas e envolvem a realização de dinâmicas em grupo, encenações nas salas de espera das UBS, grupos focais (jovens, idosos, mulheres, grávidas), programa de rádio com dicas de saúde, formação de agentes multiplicadores de saúde, capacitação de merendeiras, desenvolvimento de hortas sustentáveis, atendimento médico especializado preceptorado e visitas domiciliares - com experiências singulares (Figura 2).

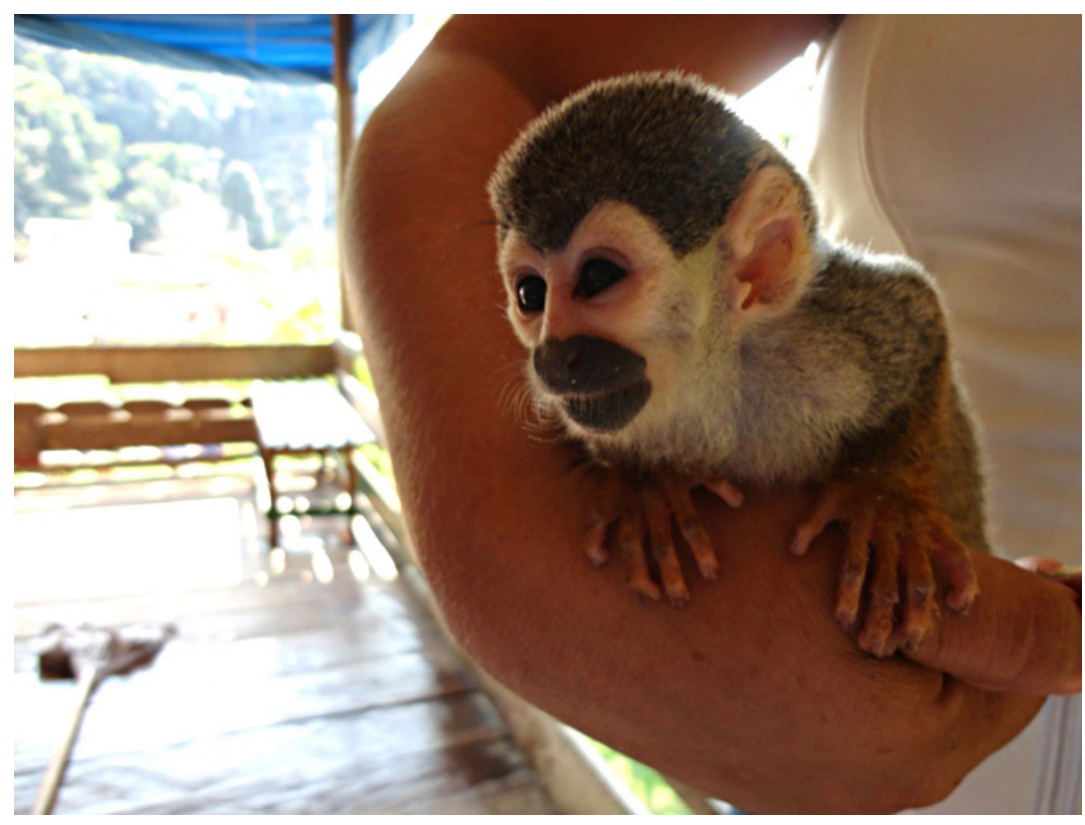

Figura 2. O macaco silvestre: anfitrião da visita domiciliar numa comunidade ribeirinha amazônica, em Itapiranga 
A linha Promoção da Saúde e Prevenção de Doenças desenvolveu os programas semanais de rádio. A rádio local disponibilizava 15 a 20 minutos para uma programação que abordava um tema em saúde, escolhido conforme as necessidades apontadas pelas equipes de saúde locais e/ou pela população.

Outro ponto que merece destaque, também, foi a formação de agentes multiplicadores de saúde. Durante a estadia dos integrantes do Programa na cidade, diariamente, no período noturno, eram realizadas capacitações planejadas pelos residentes multiprofissionais em parceria com os graduandos, que buscavam empoderar pessoas representativas na interface comunidadegestão, sobre temas de saúde ${ }^{10}$.

Os agentes mantinham contato com a equipe do Programa através de meios digitais e se tornavam referência em saúde para população, sendo que, entre outras atividades, eram responsáveis pela continuidade do programa semanal de rádio. Os relatos dos acadêmicos mostraram a mudança do olhar de cada um para a importância de construir ações que garantissem a longitudinalidade do cuidado, mesmo na ausência da equipe em campo ${ }^{10}$.

Ainda nesta linha, com o grupo de idosos de uma das cidades, realizou-se uma atividade lúdica na qual cada participante era convidado a rasgar um coração de cartolina vermelha, caso tivesse vivenciado alguma situação pejorativa ou de preconceito proferida pelos mediadores da ação.

Com o coração rasgado em pedaços, posteriormente, eles eram convidados a reconstruí-lo em folha de papel A4, tendo o auxílio de cola branca. Em seguida os idosos decoravam as emendas com miudezas (miçangas, colas coloridas, purpurinas). E, por fim, eles refletiam sobre os sofrimentos, as cicatrizes deixadas e a possibilidade de reconstruir os sentimentos com novas lembranças positivas.

A atividade contou com a integração de uma docente cirurgiã-dentista, uma residente fisioterapeuta e os acadêmicos de medicina. Dentre os relatos, predominaram a observação quanto ao preconceito, sofrimentos e angústias que acometiam este público, bem como os aprendizados vividos e compartilhados pelos idosos durante a dinâmica, que contribuíram para uma visão humanizada do cuidado.

Os gestores também eram abordados pela equipe, e, em uma das ocasiões, os funcionários de um centro de atenção aos deficientes físicos, num dos municípios, foram convidados a participar de uma oficina para refletir sobre as dificuldades, contribuições e vivências do trabalho com esse público. Um boneco grande, construído de papel sulfite, sem uma das pernas, foi a base escolhida pela residente fisioterapeuta e um acadêmico de medicina para realizarem uma tempestade de ideias.

Diante disso, a partir das palavras que surgiram, iniciouse uma discussão entre os participantes sobre o trabalho com o paciente deficiente físico e os mediadores buscaram valorizar os profissionais que ali estavam. Os registros avaliados mostram que a dinâmica foi um momento terapêutico para os gestores, assim como, um intermédio a fim de levar até a gestão os problemas vivenciados pelos deficientes no dia a dia, outrora observados pela equipe do Programa.

Já na linha Saúde da Mulher, diante da epidemiologia do câncer de colo de útero e de mama no estado do Amazonas, buscou-se, mormente, sensibilizar as mulheres quanto à importância da realização da colpocitologia oncótica (preventivo) e o autoexame das mamas. Todavia, mais importante que incluir as mulheres nesta orientação, foi à percepção da equipe no sentido de orientar também os homens sobre a saúde da mulher, levando em conta uma questão social e ainda prevalente da submissão feminina perante o homem.

Nestes municípios, entre as atividades realizadas com este fim, destacaram-se as orientações domiciliares ofertadas durante as atividades da linha de Avaliação dos Serviços de Saúde, as ações educativas em salas de espera das UBS e a realização de metodologias ativas com grupos focais.

No que diz respeito às metodologias de promoção da Saúde da Mulher, ganha destaque a ação denominada "Peito Amigo", que resultou em um mural de ideias construído pelas usuárias em um grande seio confeccionado com papel sulfite. Após o compartilhamento de conceitos e figuras, mostrados com auxílio de projetores de imagem, elas passavam por um segundo momento no qual eram questionadas ou recebiam incentivo para reflexão sobre a saúde da mama.

As mulheres seguiam com o registro dos pensamentos em pequenos papéis, que compunham ao fim o mural de ideias. Os participantes desta dinâmica destacaram a importância de aproximar os saberes populares dos científicos, sentindo-se importantes como mediadores no papel de construir conceitos a partir dos conhecimentos que essas mulheres já traziam consigo.

A Saúde da Mulher também contemplou as salas de espera do pré-natal. Encenações, rodas de conversa e tempestades de ideias compartilhavam informações importantes sobre a gestação. Em uma destas abordagens, as mulheres falavam em voz alta crenças e costumes populares sobre a gravidez, e, então, graduandos em medicina junto aos residentes de enfermagem, fisioterapia e nutrição esclareciam os mitos e verdades ${ }^{11}$.

Os saberes populares e científicos novamente foram aproximados sem estratificação e/ou grau de importância. O grupo relatou o aprendizado obtido quanto a costumes até então desconhecidos, dos quais muitas gestantes desmistificavam umas às outras, classificando o momento como um ganho maior de conhecimento do que uma oferta: o campo como instrumento de aprendizado ${ }^{11}$.

A linha Alimentação Saudável manteve a parceria, sobretudo da docente nutricionista e das residentes multiprofissionais da nutrição com os graduandos em medicina. Nas escolas foram desenvolvidas atividades lúdicas sobre higiene bucal e boa alimentação, tendo como meio o teatro de fantoches.

Outras atividades que colaboraram com a formação médica técnica, na parte nutricional, foram a avaliação antropométrica das crianças, com estratificação de risco para desnutrição e obesidade, e a aplicação do recordatório alimentar. As ações resultavam em orientações direcionadas para o processo de reeducação alimentar em infantes. Os graduandos destacaram o aprendizado junto às residentes, no que diz respeito a orientações essenciais para a mudança de hábitos alimentares e a melhor forma de abordar os usuários a fim de aumentar a adesão.

Ainda na linha Alimentação Saudável realizou-se a capacitação de merendeiras com enfoque no processo de armazenagem e seleção dos alimentos, produção da merenda escolar, conservação e transporte, assim como, a valorização da merendeira como instrumento da boa alimentação dos escolares ${ }^{12}$.

As merendeiras também passaram a conhecer a dinâmica de distribuição da merenda escolar, que diariamente percorria grandes distâncias para abastecer escolas longe da sede por via fluvial. A capacitação findou-se com a criação de hortas sustentáveis, cultivadas em garrafas PET, sobretudo para a produção de temperos frescos no quintal da cozinha, a 
fim de serem utilizados cotidianamente. O aprendizado sobre organização e gestão foi marcante para o grupo ${ }^{12}$.

A construção de um intestino gigante, uma das principais atrações em todos os municípios, foi um dos resultados da linha Alimentação Saudável. Uma estrutura de vários arcos, confeccionados de tubo PVC e cobertos por tecido TNT formavam um corredor tortuoso que era à base de um intestino magnificado, da boca ao ânus.

Ao entrar pela boca observavam-se as comidas ingeridas. O processo de digestão era vislumbrado no interior do intestino, com o auxílio de sacolas transparentes que mimetizavam alimentos digeridos em cada uma das fases. As paredes virtuais do órgão mostravam orientações alimentares e os benefícios e malefícios da alimentação escolhida. As crianças se mostravam eufóricas com o passeio dentro de um imenso intestino.

Ao sair pelo ânus, sensibilizados, os participantes optavam por mudanças no hábito alimentar. Toda equipe do programa trabalhava nessa atividade e avaliaram-na como uma forma criativa e singular de abordagem para a alimentação saudável.

Outro foco do programa foi à linha de Avaliação dos Serviços de Saúde que representou, sob os olhos de toda a equipe, uma grande surpresa. Destinados à pesquisa de campo e aplicação domiciliar de Instrumento de Avaliação da Atenção Primária (PCATool) todos os integrantes se revezavam na atividade de ir ao campo, de casa em casa.

Deste modo, ao considerar que a caminhada era o principal transporte dentro dos municípios, houve a vivência dos Determinantes Sociais em Saúde de uma forma única. Com isso, vislumbrou-se questões pessoais, culturais, comunitárias, ambientais e políticas envolvidas no processo saúde-doença. E, ainda, a ida ao domicílio foi um instrumento de promoção da saúde, sobretudo da saúde da mulher. Além disso, buscou-se também orientar as famílias quanto ao funcionamento da Rede de Atenção à Saúde do município, desconhecida pela maioria.

Por fim, a linha da Dermatologia atuou em doenças que representavam problemas de Saúde Pública. A demanda popular, assim como os grupos de risco com fotodano intenso (trabalhadores rurais e pescadores) foram avaliados por meio de atendimento individual especializado em dermatologia, realizado por especialistas, residentes de dermatologia e graduandos em medicina.

Os grupos focais em salas de espera abordaram os efeitos deletérios da exposição ao sol para a pele e reforçaram a importância da proteção solar. Outra atividade desta linha que ganhou destaque foi à triagem, diagnóstico e tratamento dos casos de pediculose em escolares, que gerou impacto para redução do número de casos e infestações.

As ações destas linhas eram realizadas ao longo dos dias em que a equipe estava no campo. Após o encerramento das atividades, diariamente, ocorria uma reunião do grupo para avaliação dos trabalhos desenvolvidos e adequações do planejamento do dia seguinte, explorando a desenvoltura, de flexibilidade, dos alunos diante da dinâmica - característica dos serviços de saúde e da gestão de pessoas.

As atividades de campos se encerravam com a organização dos materiais coletados, reunião com gestores para apresentação de resultados prévios e planejamento de ações para as visitas subsequentes ao município.

$\mathrm{O}$ retorno à Universidade, na capital Manaus, seguia com novas reuniões do grupo que compilava os dados coletados e organizava os resultados que, então, eram apresentados e discutidos em reuniões internas para a confecção de relatórios e novos indicadores que foram entregues à gestão do município. Além disso, tudo o que foi coletado serviu como base para as próximas visitas. É possível, assim, compreender a importância da avaliação das atividades desenvolvidas, seus resultados na comunidade e o processo contínuo da assistência à saúde.

Assim, discentes e docentes compartilham do mesmo pensamento sobre a extensão universitária, definindo-a como complemento importante de uma formação médica que não seja exclusivamente técnica, mas sim, crítica, sensível ao contexto em que se insere o usuário e mais apta a trabalhar na comunidade e no Sistema Único de Saúde (SUS).

\section{DISCUSSÕES}

É desafiador articular o ensino, o serviço e a comunidade por meio de ações que respondam às necessidades e interesses dos comunitários e que, ainda, possibilitem uma interação dos acadêmicos com a sociedade. Portanto, é este desafio que a extensão universitária tenta vencer ao desenvolver atividades com característica teórico-prática em uma relação dialógica da academia com a comunidade, buscando uma troca de saberes entre graduandos e usuários ${ }^{13}$.

A extensão permite o desenvolvimento da corresponsabilidade entre os futuros profissionais e a comunidade sobre o processo de adoecer, além de possibilitar que os acadêmicos conheçam as realidades e os problemas comunitários e realizem medidas propositivas face às necessidades sociais. Igualmente, essas atividades contribuem para o empoderamento dos indivíduos sobre os direitos que possuem, por meio do compartilhamento de informações, tendo a academia como mediadora $^{14}$.

A saúde é indissociável do contexto e das experiências singulares do usuário, portanto, para cada indivíduo ela será diferente. Deste modo, caminhar pelas ruas observando as condições socioeconômicas da população, estar em contato direto com os usuários inseridos na sua realidade, indagando-os sobre a saúde e a qualidade do serviço prestado, permitem que o futuro profissional possa compreender o contexto e a complexidade do conceito da palavra saúde. Desta forma é possível vivenciar a complexa tríade academia - sistema de saúde - usuário ${ }^{15,16}$.

Outro destaque é a contribuição para a atuação do profissional na prevenção primária, pois ele aumenta a prática no planejamento e execução de atividades educativas baseadas em processos de ensinagem não unilaterais, e que considerem as necessidades da comunidade e as peculiaridades regionais. Assim, faz-se necessário adaptar as técnicas à realidade local, costumes, crenças e linguagem, bem como associar saberes populares aos conhecimentos técnico-científicos, para atingir a transposição didática ${ }^{17,18,19}$.

A interação com os multiprofissionais em saúde, de maneira complementar, permite a sensibilização do graduando quanto à maior abrangência nos cuidados que uma equipe multiprofissional pode trazer ao usuário e os benefícios das visões complementares no cuidado ao doente ${ }^{20}$.

\section{CONSIDERAÇÕES FINAIS}

As atividades desenvolvidas pelo Programa Saúde e Cidadania demonstram uma tendência na educação médica para 
valorizar a extensão universitária.

Portanto, integrar acadêmicos de medicina com a comunidade estabelece, não só, a corresponsabilidade entre o futuro profissional e o usuário sobre o processo de adoecer, mas também, mostra a influência do contexto, das peculiaridades regionais e dos Determinantes Sociais em Saúde neste processo.

Os graduandos são empoderados do funcionamento das Redes de Atenção à Saúde, bem como, desenvolvem habilidades

\section{REFERÊNCIAS}

1. Brasil. Ministério da Educação, Conselho Nacional de Educação, Câmara de Educação Superior. Resolução CES $\mathrm{n}^{0} 3$ de 20 de junho de 2014, institui diretrizes curriculares nacionais do curso de graduação em medicina e dá outras previdências. Brasília: Ministério da Educação; 2014.

2. Lima DP, Garbin CAS, Saliba NA, Moimaz SAS. A importância da integração universidade e serviços de saúde. Rev Ciênc Ext (São Paulo). 2010;6(1):129-37. Disponível em: http://ojs.unesp.br/index.php/revista_proex/article/ view/60/333.

3. Ferreira RC, Da Silva RF, Aguer CB. Formação do profissional médico: a aprendizagem na atenção básica de saúde. Rev Bras Educ Med (Rio de Janeiro). 2007;31(1):52-9. doi: http://dx.doi.org/10.1590/S0100-55022007000100008.

4. Araujo MAM, de Almeida LL, Del-Masso MCS, Kogiso OK, Louro DW. Extensão universitária um laboratório social. São Paulo: Cultura Acadêmica; 2011.

5. Ayres JRCM. Extensão universitária: aprender fazendo, fazer aprendendo. Rev Med (São Paulo). 2015;94(2):75-80. doi: http://dx.doi.org/10.11606/issn.1679-9836.v.94i2p75-80.

6. Quivy R, Campenhoudt LV. Manual de investigação em ciências sociais. 2a ed. Lisboa: Gradiva; 1998.

7. Cavalcante BLL, Lima UTS. Relato de experiência de uma estudante de enfermagem em um consultório especializado em tratamento de feridas. J Nurs Health (Pelotas). 2012;2(1):94103. Disponível em: http://periodicos.ufpel.edu.br/ojs2/index. php/enfermagem/article/view/3447/2832.

8. De Alencar Roberto SB, de Souza SG, Cabral SAAO, de Alencar MCB, de Almeida FB, de Alencar EB. Ferramentas de gestão: apoio matricial como elo fortalecedor nas ações de vigilância ambiental em uma região de saúde. Rev Bras Educ Saúde (Pombal). 2015;5(4):5-9. Disponível em: http://www.gvaa.com.br/revista/index.php/REBES/article/ view/3729/3377.

9. Bauer MW, Gaskell G, organizadores. Pesquisa qualitativa com texto, imagem e som - um manual prático. 2a ed. São Paulo: Vozes; 2008.

10. Preslei AKA, Lima TMS, Martins RG, Souza CSM, Moysés RPC, Lima RTS. Tecnologia social e prática educativa sobre osteoporose para um grupo de agentes promotores de saúde segundo a abordagem dialógica. Saude Transf Soc (Florianópolis). 2012;3(4):25-30. Disponível em: http://stat. cbsm.incubadora.ufsc.br/index.php/saudeetransformacao/ article/view/1851/2250.

11. Lima TMS, Preslei AKA, de Morais LS, Moysés RPC, Lima de planejamento e adaptação para a transposição didática. Além disso, em contato com os multiprofissionais da saúde, eles tornamse sensíveis à atuação da equipe multidisciplinar e a sua função complementar no cuidado.

As vivências neste programa de extensão colaboraram para integrar criticidade, humanização e trabalho em equipe à formação técnica da grade, possibilitando que se formem médicos mais sensíveis às propostas do SUS.

RTS, Souza CSM. Tecnologia social e práticas educativas para promoção do aleitamento materno no município de Itapiranga, Amazonas. Saude Transf Soc (Florianópolis). 2012;3(3):1126. Disponível em: http://stat.cbsm.incubadora.ufsc.br/index. php/saudeetransformacao/article/view/1856/2166.

12. Rabelo ALD, Correia RP, Moura CSS, Lima RTS, Bicalho NPD, Schereiner IMO, Martins RG. A merenda chegou! Uma estratégia inovadora na produção e distribuição de merenda escolar em uma realidade ribeirinha amazônica. Saude Transf Soc (Florianópolis). 2012;3(3):52-6. Disponível em: http:// stat.saudeetransformacao.incubadora.ufsc.br/index.php/ saudeetransformacao/article/view/1836/2150.

13. Jezine, E. As práticas curriculares e a extensão universitária. In: $2^{\circ}$ Congresso Brasileiro de Extensão Universitária; Belo Horizonte, $12-15$ set. 2004. Anais. Belo Horizonte: UFMG; 2004. p.1-5. Disponível em: https://www.ufmg.br/congrext/ Gestao/Gestao12.pdf.

14. Pelicioni MCF, Pelicioni AF. Educação e promoção da saúde: uma retrospectiva histórica. Mundo Saúde (São Paulo). 2007;31(3):320-8. Disponível em: http://www.saocamilosp.br/pdf/mundo_saude/55/02_restrospectiva_historica.pdf.

15. Czeresnia D, Maciel EMGS, Oviedo RAM. Os sentidos da saúde e da doença. Rio de Janeiro: Fiocruz; 2013.

16. Ceccim RB, Feuerwerker LCM. O quadrilátero da formação para a área da saúde: ensino, gestão, atenção e controle social. Physis (Rio de Janeiro). 2004;14(1):41-65. doi: http://dx.doi. org/10.1590/S0103-73312004000100004.

17. Gadotti M. Lições de Freire. Rev Fac Educ (São Paulo). 1997;23(1-2). doi: http://dx.doi.org/10.1590/S010225551997000100002.

18. Vasconcelos EM. Redefinindo as práticas de saúde a partir de experiências de educação popular nos serviços de saúde. Interface (Botucatu). 2001;5(8):121-6. doi: http://dx.doi. org/10.1590/S1414-32832001000100009.

19. Anastasiou, LGC. Ensinar, aprender, apreender e processos de ensinagem. In Anastasiou LGC, Alves PL. Processos de ensinagem na universidade: pressupostos para as estratégias de trabalho em aula. 6a ed. Santa Catariana: Univille; 2003. p.11-38.

20. Flores CH, Beckenkamp K, De Oliveira MB, Da Silva RK, Da Silva ACF. Atuação de uma equipe multiprofissional em um serviço de reabilitação física. In: "IV Salão de Ensino e de Extensão"; Santa Cruz do Sul, 21-25 out. 2013. Anais. Santa Cruz do Sul: Unisc; 2013. p.122. Disponível em: http://online. unisc.br/acadnet/anais/index.php/salao_ensino_extensao/ article/view/11063. 